Institution; and it is understood that the committee of the National Educational Association on the question of establishing a National University in Washington approves the plan and purposes of the Washington Memorial Institution. The Washington Aca demy of Sciences, having turned over to the new organization the conduct and maintenance of the Washington Memorial Institution, will now cooperate with the George Washington Memorial Association in the erection and maintenance of a memorial building to be dedicated to science, literature and the liberal arts.

ADDRESS OF THE PRESIDENT OF THE AMERICAN MEDICAL ASSOCIATION.*

IN approaching the discharge of my duties as presiding officer of the fifty-second session of the American Medical Association, I beg to express my appreciation of the generous suffrages by which I have been called to a position of such conspicuous honor. This appreciation becomes all the more pronounced when I reflect upon the magnitude and achievements of this great national body and upon the luster of the distinguished men who have presided over its deliberations. This thought brings me to the first duty of the occasion, and that is officially to bring to your attention the fact that since our last reunion three of $m y$ most illustrious predecessors have been called from their worldly activities to the realm of rewards. Alfred Stillé, Lewis A. Sayre and Hunter McGuire, each a former president of the Association, died within a single week. Their lives were known of men, their records are ornaments of our annals, and their achievements are their eulogies. They labored zealously and with beneficent results, not alone in the scientific field, but in behalf of an organized national profession ; and to guard zealously

\footnotetext{
*Delivered before the Fifty-second Annual Session at Saint Paul, Minn., June 4, 1901.
}

the splendid legacy which they, among others, have left us, must be one object of our labors upon this auspicious occasion. The hope is indulged that steps may be taken to procure suitable portraits of these and of other deceased presidents of the Association, to be placed in some safe gallery until such time as the Association may be able to transfer them to its own Temple of Fame. I recommend that suitable formal action be taken on this occasion relative to the life, distinguished services and the death of these lamented confreres.

\section{FOREIGN RELATIONS OF THE AMERICAN} MEDICAL ASSOCIATION.

The American Medical Association accredited delegates during the last year to several foreign medical conventions, notably the International Medical Congress at Paris, the Dominion Medical Association of Canada, the Mexican National Association and the Pan-American Medical Congress at Havana. To each of these organizations the American Medical Association sustains relations of peculiar intimacy. As one of the great scientific nations of the earth, the United States is naturally an integral part of the International Medical Congress. This Association, by a resolution presented by your present executive officer, took the initiative in 1891, in organizing the PanAmerican Medical Congress. The first reunion of that Congress was held in Washington in 1893, under the presidency of the late lamented Dr. William Pepper. The second was held in the City of Mexico in 1896 under the presidency of Dr. Carmona y Valle, while the third has been held during the last few months in the City of Havana under the distinguished presidency of Dr. Juan Santos Fernandez. This movement has for its object the establishment of closer relations between the medical profession of the different countries of the Western Hemisphere. It has already 
borne excellent fruit in the increased patronage of our medical schools from the far south, in the improved status of American medical practitioners in Latin America, in a better understanding of quarantine questions in the different countries, and in the development of a concert in the investigation of the medicinal flora of the Western Hemisphere. Our relations with the medical profession of Canada must be of increasing intimacy, and I indulge the hope that, while maintaining the national limitations of our Association for delegate and legislative purposes, its membership, with the privilege of participating in all scientific matters, may be freely opened to our brethren who live beyond our immediate borders.

FISCAL AFFAIRS AND THE JOURNAL:

It has passed into unwritten law, born of the gradually developing features of our organization, that your president shall restrict his annual address to a discussion of the affairs of the Association and to the great object to which, by the terms of its Constitution, it stands consecrated-' the common interests of the medical profession in every part of the United States.' In compliance with this rule, and realizing that $I$ am leaving scientific questions to be presented by orators appointed for the purpose, I have pleasure in calling your attention to the satisfactory condition of the affairs of the Association, as indicated by the consolidated report of the Treasurer and of the Board of Trustees. From it you will observe that under the judicious management of your Board of Trustees you had a cash balance at the end of the last fiscal year of $\$ 31,004.67$, being an excess of $\$ 3,696.66$ over the preceding year. Your plant has been increased in value to the amount of nearly $\$ 10,000.00$, and the net profits of the Journal amounted to nearly $\$ 14,000.00$. You will be gratified to realize that, in ad- dition, you have safely invested as part of a fund with which to buy a home for the Journal and for the Association, the respectable sum of $\$ 25,000.00$. If, however, you have occasion to feel satisfied with the normal condition of your finances, you must contemplate with pride the rapid increase of your Journal, in quality, size, circulation and influence. The average weekly circulation grew, during the last fiscal year, from 13,672 to 17,446 , and I have added pleasure in informing you that, since the period covered by the report, the weekly circulation has grown to 22,000 copies. For the accomplishment of these splendid results, I feel that you will join me in hearty acknowledgment, not only of the sagacious management by the Board of Trustees, but the tireless industry and the discreet direction of our accomplished editor, Dr. George H. Simmons.

I feel that it is important, however, to call your attention to the fact that it would have been impossible for your Board of Trustees to have accomplished these results if, through its action, the Association had not become incorporated. Leases were to be executed, purchases were to be made, contracts were to be entered into, money was to be loaned and bonds were to be exacted, to do all of which it was necessary that the Association should become a legally organized corporation. This was affected, $a d$ interim, by the action of your Board of Trustees, which procured articles of incorporation under the laws of Illinois, bearing date of April 14, 1897. I am not aware that this fact, attested by the document which I have laid before the Executive Committee, has ever been confirmed by the vote of the Association. I recommend, therefore, that such action be taken at the present session.

If, however, the condition of the Association, and particularly of the Journal, is, on the whole, occasion for much satisfaction, 
certain facts revealed by the report are food for thought. Thus, the Journal has an aggregate circulation two and one-half times greater than the aggregate membership of the Association. It would seem, therefore, that while the profession at large prizes the Journal, it places relatively less than half as much value upon membership in the Association. This fact becomes strikingly significant when it is remembered that membership can be acquired by those who are eligible at no additional expense and with but trifling inconvenience. Does the Journal fulfill all the wants of the profession arising in connection with the Association? Are there no additional advantages to be derived from membership? Is there a lack of esprit du corps-a lack of the sense of unity in the profession? Is the existing basis of our national organization distasteful to the majority of the practitioners? Do our subscribers embrace a considerable number of practitioners, who, under existing rules, cannot become members, and whose influence, therefore, cannot be secured in behalf of the Association? These are questions that I am at liberty to ask, and that you are at liberty to answer.

Another thought suggested by the report relates to the disposition of the accumulating surplus. Shall the present policy for creating a fund for the purchase of property be carried out? Shall a larger proportion of the money be expended in still further exploiting the Journal? Shall the members receive a direct advantage from the earnings of the property which they have created, by reducing the annual dues, or shall a certain proportion of our surplus be expended in conducting original scientific investigations on subjects of universal interest to the profession? I cannot resist the temptation in this connection to venture replies to these questions far enough to say that, in my opinion, a reserve should be held in hand large enough to meet any pos- sible contingencies that might occur by fire or other disaster in connection with the Journal; that the present generous policy in promoting the welfare of the Journal should be continued; that the dues of the Association should not be decreased; and that the question of establishing and defraying the expenses of certain commissions for special scientific investigators should be taken under serious consideration. The question of tuberculosis is not yet a closed chapter. The causation of cancer is yet a sealed mystery. The problems of tenementhouse reform are not yet solved. The prevention of various endemic diseases has not yet been made practicable. The systematic investigation of the American medicinal flora, begun under the auspices of this Association more than forty years ago, remains an uncompleted task. These are a few among the many objects of a specific character which demand and should receive the fostering care of the Association.

I feel, however, that at the present moment, and under the existing features of our organization, it would be almost impossible to determine, judiciously, either of these very important questions, and I now bring them before the Association only for the purpose of directing attention to them, with the hope that they may be taken up subsequently, and under more auspicious circumstances.

SCIENTIFIC WORK OF THE ASSOCIATION.

The Association began its career with general meetings, devoted chiefly to questions of medical education and professional conduct and to lengthy reports from various standing committees. In 1860 it divided itself into a few sections, each with a certain autonomy, and each devoted to a particular part of our great scientific work. This change was followed by the establishment of the Judicial Council, by which means controversial questions, many of 
them of a personal character, were eliminated from the general meetings. The subsequent creation of the Executive Committee still further relieved the general meetings of annoying details. Thus relieved, both the general meetings and the sections have grown in scientific importance, emphasizing the persistence of our devotion to what must ever be recognized as the essential, fundamental object of our organization-the cultivation of the medical sciences. It must be acknowledged, however, that great as has been the progress in this particular, too much of the time of our general sessions is yet devoted to the consideration of matters which might, with propriety, be relegated for final action to a smaller body. It would redound largely to the interest of our annual session if the general membership could be entertained and instructed at our general meetings by exercises of a more purely scientific character, of such broad nature that they should not be restricted to any of the sections. A reform in this particular will be a long step in the direction of progress. The sections, in consequence of the faithful labors of their officers, offer strikingly attractive programs for the present session. In several of the lists will be found the names of invited guests who, through fortuitous circumstances, are not members of the Association, but who are, nevertheless, active workers in the scientific field, and whose participation in our labors will enrich the value of our proceedings and enhance the felicities of the occasion. I bespeak for them your cordial welcome. While the officers of sections and your president have exercised the prerogative of inviting guests, who come as guests, and not as members of any class, as specified by the Constitution, such invitations have been extended solely with the object of advancing the interests of the Association. I look upon this privilege, which has been exer- cised by all of my predecessors and by previous officers of sections, as one of extreme importance, and one which should be continued under any plan of reorganization which may be adopted. It is my conviction, however, that the privilege should be hedged about by certain limitations, one of the most important of which should be that an invitation should not be extended a second time to any person residing within the United States whose professional qualifications may entitle him to membership. With reference to the invitation of persons identified with the allied sciences, the matter should be left absolutely to the discretion of the president of the Association and with the officers of sections.

\section{CONGRESSIONAL AND STATE LEGISLATIVE} AFFAIRS.

The American Medical Association, dur. ing the first fifty years of its existence, exerted relatively little influence upon legislation, either State or national. Since the standing Committee on National Legislation and the National Legislative Council of delegates from the State Societies have been established, and have become cooperative, there is some evidence that the voice of the profession is headed at Washington. The experience of the splendid committee of this Association, acting in concert with the National Legislative Council during the last year, has, however, shown the serious necessity for more thorough organization in protecting the interests of the profession and the interests of society, as represented through the profession. The inefficiency of our present organization for influence upon Congress was shown in the inability of your committee, notwithstanding its strong personnel and the influences at its command, to prevent the degradation of the army medical service. This was accomplished by the passage of a bill under the cham- 
pionship of Senator Hawley, by the terms of which the medical corps of the army is subjected to unfair and humiliating discrimination. This law grades the medical department for rank, promotion, and, in consequence, for pay, below every other department and special corps of the army, and, with the exception of second lieutenants, it is graded below the line. In accordance with its provisions, a medical officer, to obtain a colonelcy, must pass through three times as many files as an officer of either the Quartermaster's, the Subsistence or the Pay Departments; more than twice as many as an officer of Engineers or of Ordinance, and nearly twice as many as an officer of the Signal Corps. The effect of this discrimination is not only to lower the rank and pay of medical officers, but must result in lessening the efficiency of the corps by repelling men of spirit and worth.

In every war known to history the deaths from preventable diseases have exceeded those due to battle. At no time has hygienic science been so resourceful as at present in preventing disease. A law which fails to give to armies, either in peace or in war, the fullest protection by the application of the latest scientific developments at the hands of specially trained medical men is unjust to the soldier, to society and to the medical profession. In view of these facts, the army reorganization law of the last Congress was inexplicable and inexcusable. It, however, forces itself upon your consideration from another standpoint. Physicians are citizens of the Republic. As such they are intellectually, socially, politically and officially the equals of any other element of the body politic. There is no station to which they may not attain ; there is no distinction of which they may not be the recipients. Their rights are of manhood origin, and their prerogatives are inherent. They are, in very fact, peers of the realm, and the peers of any peers of any realm. When the status of any number of physicians in their representative relationship to society is lowered, the status of the medical profession in general is menaced in corresponding degree. When the Congress, by the enactment of a law, degrades, relatively, the status of an important body of medical men engaged in the public service, it strikes at the status of every physician in the country. It becomes, therefore, the duty of every member of the medical profession, jealous of his rights, his prerogatives and the fair name he may leave his children to resent, as personal between himself and every member of the Congress who voted for this law, the action which cast a stigma upon our profession.

It has been the conviction of many enlightened members of the medical profession that the means employed by the general government for the protection and promotion of the public health are capable of improvement. These duties have devolved upon the Marine Hospital Service, which was originally designed to give succor to unfortunate people, without other domicile, who were employed upon our rivers, lakes and the high seas. With the growth of sanitary science this service, being the only established agency available by the government for this purpose, has been largely diverted from its original object. As a result, under the present wise administration of its Surgeon-General, its representatives are abroad investigating the sauitary condition of foreign cities, its agents are at our ports beating back threatened epidemics, while valuable investigations are being conducted in its laboratories. In the exercise of its quarantine functions, however, it comes in conflict with the police power that is guaranteed by the Constitution to the different States. The friction thus engendered has been especially marked 
in the seaboard States. While this is true, the Marine Hospital Service, in scope and design, does not fulfill in highest degree the objects of a central coordinating agency for the protection of the public health. It was thought to create a Department of Public Health, with its executive officer in the cabinet, but this idea yielded to that of a bureau in charge of a large Advisory Council, composed of representatives from various States. Resolutions have been adopted and memorials have been sent to the Congress, committees have been appointed, money has been appropriated by this Association, bills have been introduced, and hearings have been had in committee, with the result that the conditions to-day are precisely the same that they were ten years ago, when the agitation was inaugurated in the session of this Association held at Washington.

Secretary Wilson, of the Department of Agriculture, in his Report for 1899, recommended that the Congress appropriate money to defray the expense of a systematic investigation of the medicinal flora of the United States and of experiments upon the neutralization of medicinal plants indigenous to other countries. This recommendation was based upon the fact that the United States is the only great country which either has not conducted or is not conducting such experiments, and upon the fact that the proposed measure, touching the avenues of industry, manufacture, commerce and the public health, was one of national concern. This measure, however, with its manifest importance, was denied even courteous consideration, while its friends were denied a hearing by the committees of the Congress.

The cause of failure on the part of this Association to procure legislation by the Congress-and, with the exception of preventing the passage of the anti-vivisection bill last year and securing the enactment of the quarantine bill this year, our, recent efforts must be recognized as failures-I say the causes of our failure are properly subjects for careful consideration. I have examined the records of the Association from the date of its organization, and have been profoundly impressed with the fact that memorials, resolution, or even more definite propositions addressed to the Congress have, for the most part, represented the views, or rather the impressions, of the individual members proposing them. They have generally been presented in the general meeting and have been endorsed without the deliberation essential for wise action; but a deliberation which is simply impossible in the limited time available in our general meetings. In certain instances memorials to the Congress have been presented at one session of the Association, have been referred to committees and reported back for action, either at a later meeting of the same session or at the succeeding annual session of the Association. But it becomes evident that this course lessens the evil but a trifle, for the reason that the committees to which such matters were referred have been constituted either under the leadership of the member proposing the measure or of members of a standing committee who had no interest in or understanding of the proposed measure. Such memorials, resolutions or propositions, when acted upon affirmatively by the general meeting of the Association, have, possibly, been mailed to some member of Congress or of a Legislature, but were not followed by effective work in the rank and file of the profession or among their patrons. When such bills have been presented to the Congress, and have received a certain amount of support from representatives of this Association, they have, as a rule, attained only that degree of importance that have made them valuable to their ostensible champions, as 
something to trade in the game and barter of legislation for something which would please a larger number of constituents and command a larger number of votes. In view of the fact that after all the argument of votes is the only one which appeals effectively to the average Congressman, it behooves this Association, in its efforts to conserve the interests of the profession and of society, to put itself in a position. to influence the largest number of votes. Every physician, therefore, should, in a perfectly respectable sense, become an active working politician. This subject, however, is of such breadth and of such depth that it may be well for us to pause at this juncture long enough to consider, from the standpoint of fundamental facts, the relationship of physicians to each other, and of the medical profession in the aggregate as an integral factor in society.

THE PROFEsSION, THE ASSOCIATION AND THE COMMONWEALTH.

In approaching a study, however brief, of the relation of the medical profession to the state or, as I prefer to call it, the commonwealth, I feel that I am inviting your attention to an eminently practical theme; one which may enable us to understand the influences by which we have arrived at our present estate, and the means by which we may advance to even greater achievements. As we approach this theme-this eminently practical theme-we discover that the status of the medical profession, like that of every other element of that complex whole which we call society, is a perfectly natural one. Whatever it may be, it has been attained in the process of evolution and has been and is determined by laws as immutable as those which govern the commingling of atoms or the sidereal strides of the planets. It is not the result of conventions or of resolutions or of statutory enactments; but these are to be interpreted rather as in- diciæ, for the time being, of the position of the profession in the body politic. They are, indeed, consequences rather than causes, and as such they are subjects for careful inquiry. It is by a study of them that we are enabled in part to determine those laws, those natural laws, our harmony with which is essential not alone for the present usefulness and continued progress of the profession, but for the ability of the medical profession to conserve the welfare and promote the happiness of society at large.

But I have said that the position of the medical profession is a natural one. The truth of this declaration is apparent when we go back to the beginnings of societywhen we examine the evidences presented by primitive peoples. We are familiar with the classic example so frequently utilized as a starting point in the discussion of sociologic phenomena-the example of the two aborigines, one of whom makes better arrows, and the other, better mats, than his companion, when, presently, one confines himself to arrows, the other to mats, each trading his own for the other's products. Here is an example of the beginning of what the scientists call 'specialization of function in the social organism.' It is an interesting process, which, based upon varying necessities and diverse aptitudes, results in multiplication of handicraft until somebody is hurt. This is a new necessity, and it is met by a new aptitude, and the possessor of that aptitude-the medicine man, our honored progenitor-steps upon the scene. His companions, appreciating his services, reward him with their arrows and mats; and he, finding the life to his liking, restricts himself to his new-found vocation-and the medical profession is established! As the necessity for his services, whether of charm or incantation, becomes more apparent, the esteem of his fellows becomes more pronounced. As events pro- 
gress he is accorded certain rights, given certain prerogatives and hedged about by certain limitations, all calculated to increase his effieiency in promoting the common welfare-and thus is the practice of medicine regulated. He is spared from the battle that he may serve his companions, and he stays away from the chase that he may delve into the great mysteries-and thus is medical education inaugurated. He is the exponent not only of his professional knowledge, but of at least the average intelligence of his people. $\mathrm{He}$ is, in short, an integral part of the primitive social fabric. As such he shares the manners, the customs, the aims, the ambitions of his companions; and he, with them, is controlled by the forces which determine the common state and the common destiny. His status is, therefore, determined by the very laws which control the growth and development of society itself. So true is this that, from the dawn of history until the present day, and in every stage of sociologic development, the civilization of a people may be infallibly determined by the intelligence, the efficiency and the influence of its medical profession.

THE MEDICAL PROFESSION AND SOCIETY FIFTY YEARS AGO.

It would not be to our present purpose to follow the evolution of society as exemplified in any of the civilized peoples, or, as the scientists say, 'distinct ethnic entities of the world,' in which the present complexity has been attained by an orderly succession of events. And it would be equally unnecessary to show, what everybody knows, that the medical profession, the heritor, in common with others, of antecedent influences, has been propelled by the same forces and by equally orderly events to precisely the same standard of civilization. The lesson before us is that of the relation of the medical profession to a society, which, but a few decades ago, was the most diverse in origin and the most heterogeneous in constitution known to modern history; but a society, which at the dawn of the twentieth century is one of the largest, richest and most intelligent of the world, a society, well amalgamated, and which, by common consent of even adverse critics, is moving in harmony with the most advanced influences of civilization. I fancy I should suddenly find myself unpopular with the audience, if I were to intimate that you, who comprise it-that you, the representatives of the medical profession-have failed to contribute your full quota to the great progress which that society in general has achieved, or that you do not reflect in intelligence and morality the highest type of civilized man. I hasten to allay your apprehension, for I have no such intention. On the contrary, I ask you to indulge with me in a retrospect of American society during the last half dozen decades that we may the better understand the important part that you, and the profession that you represent, have played in the attainment of present results.

As I have already stated, the middle of the nineteenth century found diverse conditions of society in the United States. The older cities of the seaboard were the centers of an advanced civilization. The remoter counties of the same States, however, were then, in the absence of railroads, the telegraph and modern mail facilities, more remote from the centers of American influence than is St. Paul to-day from St. Petersburg. The great tide of emigration that had already poured and was yet pouring over the mountains and spreading in lonely habitations or widely separated communities over the vast valley of the Mississippi from the lakes to the gulf was busily engaged with the serious problems of existence. The forest was to be felled and the prairie was to be subjugated, habitations were to be 
built and crops were to be raised. In the midst of these exactions, institutions of higher learning were established, and to an extent patronized, and some strong men were produced. But it must be recognized as true that society in general had but little time and less money to devote either to schooling or to the amenities of life. The medical profession, under these circumstances, was precisely like the community of which it was a part. There were but few medical colleges, and they, for the most part, were but meagerly equipped. Many doctors became such while going from one town to another. Ignorant inventors of alleged systems of cure hawked their wares in the highways and the byways. Dogmatism that was destructive to intelligence was rampant, while schism was fostered by the baneful commercialism that too generally pervaded the heterogeneous mass of forty thousand people that comprised the medical profession. In eight of the twenty-six then existing States, no laws affecting medical practice had ever been enacted; in eleven, laws previously enacted had been repealed; in three only were there any restrictive laws, and these proved inefficient; while the facts could not be ascertained relative to the remaining four States.

THE ERA OF ATTEMPTED VOLUNTARY REGULATION OF MEDICAL PRACTICE.

To remedy these evils, and actuated by the love of science, the promptings of selfinterest, and by devotion to the interests of humanity, representatives of the various State medical societies met in convention over half a century ago and organized the American Medical Association, with the avowed object of having its members represent and take cognizance of 'the common interests of the medical profession in every part of the United States.' It sought to cultivate medical knowledge among its members, to elevate the standard of medi- cal education, to promote the honor and influence and interests of the medical profession and to enlighten the public concerning the relation between the medical profession and society. Emulation and concert of action in the profession and friendly intercourse among those engaged in it were additional aims of the founders of this great body of representative American medical practitioners. A constitution, by-laws and certain rules of conduct were adopted. The constitution provided for a delegate body, delegates being accredited from recognized medical societies, medical schools and eleemosynary institutions. The rules of conduct prescribed in detail the deportment of a physician, the deportment of the patient; interdicted the licensure of sectarian physicians, and proscribed from consultation those whose practice was based upon an exclusive dogma. The influence of the new Association was extended chiefly through the avenues of the various State societies, many of which adopted the rules of conduct that had been prescribed by the newly formed national body as the basis of affiliation. Several of the State societies, notably those of Massachusetts, Rhode Island and Mississippi, finding either that the prescribed rules of conduct were not suitable to their respective local conditions, or feeling that they were sufficiently in touch with the ordinary forces of civilization to require no such formulæ, never adopted the rules of conduct prescribed by the national body. The medical association of Alabama adopted the rules with rather a naïve proviso that somebody be appointed to call attention to such of the special teachings of these rules 'as may seem to require elucidation in view of special circumstances and conditions.' Other State societies adopted more or less modifying resolutions, but the general spirit of ostracism and aloofness was maintained during the succeeding three decades. The 
result of this movement was immediately salutary; it developed an esprit $d u$ corps in the great body of the profession; it gave an authoritative definition to medical education and it created a strong and influential national body within the profession. At the same time, however, it became apparent that the organization did not possess the necessary inherent strength to accomplish its avowed object to regulate the practice of medicine. As time passed schismatic medicine grew apace, its colleges multiplied, its practitioners appeared all over the country, exemplifying that law that always makes the blood of the martyrs the seed of the church. Quackery of the most flagrant character was found everywhere, and society was unprotected from its ravages, while the inability of a voluntary unchartered organization to enact and to execute plenary laws was reduced to a demonstration. The medical profession, as an organized body, discovered that its relation to the commonwealth was, as the result of its own proscriptive policy, scarcely more intimate or more influential than at the beginning of the thirty years hopeless experiment.

\section{THE ERA OF EFFECTIVE LEGISLATIVE CONTROL} OF MEDICAL PRACTICE.

The era of effective legislative control of medical practice came as the natural reaction from the demonstrated failure to accomplish the same result through voluntary organization; but it came as the result of the sentiment which had been propagated largely through the influence of this Association. The representatives of progressive medicine, turning from the National Association, invoked the aid of their respective State societies in taking up the question with their respective legislatures. The profession in each State, however, recognizing its own local conditions, proceeded in its own way to attend to its own business. The very earliest attempts to secure State legislation revealed the fact that the so-called irregular practitioners, under the stimulus of ostracism and the fostering care of public sympathy thereby induced, had become so numerous and so influential that, in the majority of States, nothing could be done without their cooperation. It was no longer a theory, but a condition, with which the real reformers were confronted-and they met it. California, in 1876, through its regular medical society, took the initiative. After conferences with the representatives of the sectarian societies, and after securing their cooperation, a law was procured creating a licensing board composed of representatives of both the regular and sectarian schools of practice. Illinois, confronted by precisely the same condition, took precisely the same course. Alabama, always progressive, but the happy possessor of other conditions, was able to place the regulation of medical practice for the time being under the control of its incomparable State medical association. Colorado created a mixed board. New York, confronted by . conditions even more complicated than those in other States, took up the same task. The profession of that State, acting through its organized body, containing among its members many of the most honored and illustrious names in American medicine, found it doubly necessary to enter into treaty with the denominational physicians. It realized, however, that the rules of conduct to which it had always conformed contained, among other provisions, one which made it unlawful to $* * * *$ examine or sign diplomas or certificates of proficiency for, or otherwise be especially concerned with the graduation of persons whom they have good reason to believe intend to support and practice any exclusive and irregular system of medicine.'

As the thing expressly interdicted by this 
rule was the very thing which it was proposed to do, and which had been done in other States, and which it was very necessary to do in New York, the medical society of that State amended the rules of conduct, so that it or its members might, at discretion, enter into professional relations with any or all persons whom the law of the State at that time recognized to be practitioners of medicine. When this action was brought to the attention of this national body, it resulted, not, as might have been expected, in the amendment or the abrogation of the rule which had grown obsolete in the march of events, but in its tacit reaffirmation and in the opprobrious excommunication, for the time being, of the entire profession of the great Empire State. This action, viewed impartially after the lapse of nearly twenty years, becomes the more extraordinary when it is observed that similar action was never taken with regard to Massachusetts or Rhode Island or Mississippi, the societies of none of which had ever adopted the prescribed rules of conduct; nor with regard to California or Illinois or Colorado, each of which had, by overt act, if not by open declaration, so far as this rule is concerned, taken an equally non-conformist position. It is not surprising that, with such an example before the State societies, the experiment in consistency has not been repeated. But the movement of effective regulative legislation, once inaugurated, happily spread with great rapidity. Mixed boards of licensure are now to be found in the majority of the States of the Union, and in the majority of such boards are to be found members of the American Medical Association engaged in issuing licenses to practitioners of exclusive dogmas, and sitting in consultation with sectarian physicians, not over a dose of medicine, but over the vastly more vital question of the qualifications of those who are to care for the sick of our Republic.
THE MEDICAL PROFESSION AND SOCIETY AT THE BEGINNING OF THE TWENTIETH CENTURY.

The result of the twenty-five years of statutory regulation of medical practice are in striking contrast with the results of the quarter of a century of attempted regulations by methods of proscription. At the conclusion of that humiliating experiment, as at the beginning of it, there was not a single effective medical practice law on the statute books of a single State of the Union. To-day there are forty-eight State or territorial licensing boards, most of them being composed of representatives of both the regular and the sectarian schools of practice. The laws of the different States are of varying efficiency, the one procured by the Medical Society of the State of New York, at the price of yetmaintained excommunication from this body, standing to-day as the model of excellence for the entire country. Under the influence of these laws, instigated by members of the American Medical Association, and which, after all, are but expressions of the sentiments of the medical profession confirmed by society at large, many substantial reforms have been accomplished. The medical schools, which in this country have labored bravely and efficiently under adverse conditions, have been stimulated to increased efficiency. One of the first changes accomplished was the practical standardization of requirements to enter practice ; and one of the first features of this standardization was to secure for the student ' the aids actually furnished by anatomy, physiology, pathology and organic chemistry'-the four cardinal studies which, strange-sounding as it seems, it was necessary solemnly and specifically to insist upon a half-century ago. It follows, therefore, that with broadened and increasingly uniform curricula, it cannot be said that schools, even of sectarian an- 
tecedents, entirely ' reject the accumulated experience of the profession,' nor can it be said that, in a sectarian sense, they any longer possess an excuse for existence. Their graduates, or such of them as do not base practice on an exclusive dogma, are, in many instances, met in formal consultation by even conservative regular physicians, and, in more than one instance, are made members of medical societies that are in affiliation with the American Medical Association.

The Illinois State Medical Society, which has always been among the foremost in reform movements within the profession, at its recent annual session, unanimously

"Resolved, That the school of graduation shall be no bar to membership in the Illinois State Medical Society, providing such physician is recognized by the local societies as qualified and not claiming to practice any exclusive system of medicine."

The Ohio State Medical Society, by precedent, if not by formal action, established the same rule.

We thus see that the proscriptive rule which, during the more than twenty-five years of its dominance, propagated the very evils it was intended to correct, is rapidly expiring by limitation in the face of new conditions that have been induced, in spite of it, by beneficent and catholic legislation. In the State of New York alone the annual registration of sectarian physicians has diminished nearly ninety per cent. under the operation of its present laws. In the State of Ohio many physicans who are graduates of sectarian schools are making application to have their classification on the register changed to 'regular,' while equal reactionary movements are observable in other States. Thus we observe the passing of homeopathy and electicism, just as did the calm scientists of Rome witness the passing of the ' humoralism,' the 'Methodism,' the ' electicism,' and the 'pneumatic school' of that period ; and just as passed the 'chemicalism,' the 'iatro-physical school,' the 'iatrochemical school,' and the 'brunonianism' and the dozen other 'isms' of later epochs, each leaving its little modicum of truth as the memento of its existence. And let us felicitate ourselves that, with the passing of the particular sectarianism of the last century, there is also the passing of its concomitant evils, such as existed in even greater degree in the time of Galen, who 'found the medical profession of his time split up into a number of sects, medical science confounded under a multitude of dogmatic systems,' and, as if relating the effect of the cause, the historian continues, 'the social status and the moral integrity of the physician degraded.' The further results of this new order of things, however, are observable, not alone in the modified curricula of the medical schools, but in the changed organic relations of the institutions themselves. Under the pressure of legal requirements the weight falls with almost fatal force, upon the small, private and poorly equipped institutions. These institutions, in the interest of self-preservation and to protect a respectable alumni, are forced either to expand their enterprises or to seek relations with universities which are deeply founded in the community ; or else actually to go out of existence. The majority of the schools seek connection with the universities, by which step alone they become logical objects for endowment, and it is to be hoped that this movement will continue until in this great country medical education shall be as firmly established as it is to-day in any of the transatlantic nations.

Another of the new conditions which has developed within the last quarter of a century, as the result of an increasing professional unity, is the efficient sanitary regulations, national, State and municipal, that now afford protection to the people from 
diseases that were formerly devastating in their effects. It is not necessary in this audience to mention smallpox, cholera, typhoid fever, diphtheria, anthrax, leprosy and the bubonic plague, each of which has been brought under relatively effective control, but $I$ do feel that it is necessary to emphasize the fact that there are many unsolved problems relating to the prevention of disease that stand as a challenge to the industry, the ingenuity and the courage of the profession. While these various changes have taken place, others of almost equal importance are observable in the relations of physicians to society. While the community, instigated by the medical profession, has given to that profession a legal status, definite and increasingly influential, and has given it certain prerogatives and certain exemptions, it has, likewise, hedged it about with certain limitations and imposed upon it certain liabilities. There are numerous laws, both common and statutory-lex non scripta and lex scripta - that admonish the physician that his conduct carries with it a liability not defined by self-imposed rules, and the numerous courts of our land proclaim that there are tribunals, 'other than his own con. science, to adjudge penalties for carelessness or neglect' on the part of the physician. So numerous, so unjust and so disastrous are actions before such tribunals that they have caused the development of a new, legitimate and beneficent enterprise in the development of a company to insure physicians against malpractice. It may be true that in certain States and localities these laws are unjust, and that there is a grave error in their administration by judges created under our wretched elective system ; but if sog the facts only emphasize anew the necessity for more complete organization of the profession and for the more active exertion of its influence upon elections.
THE REORGANIZATION OF THE ASSOCIATION. This brings us again to a realization of the fact that the results that can be achieved only by the unification of our national profession can not be attained under the present organization of our Association. The disproportionately rapid growth of the Journal as compared with that of the Association can have no other significance. The weakness of the Committee on Legislation, at Washington, was a question neither of personnel nor of industry, but arose purely from the fact that there was no efficient organization in the rank and file of the profession by which speedy and effective influence could be brought to bear upon members and senators. Equal difficulty has been encountered in several States where organization has been similarly defective. The demand for more effective organization of the Association has come from all over the country and resulted in the adoption of a motion, at Atlantic City, authorizing the appointment of a committee of three to re.port a plan of reorganization at this session. Another motion was adopted authorizing the creation of a supplementary committee of one from each State and territory, entitled a Committee on Organization, which has been filled byappointing for the most part the retiring presidents of State societies for the current year. The committee on reorganization, consisting of Dr. J. N. McCormick, Kentucky, Dr. Geo. H. Simmons, of Illinois, and Dr. P. Maxwell Foshay, of Ohio, has given to the important question entrusted to it a most careful and painstaking consideration. It has laid before you the results of its deliberation. In doing so it has emphasized the principle that this Association has its origin in the organized profession of the respective States. It emphasizes the fact that the delegate body should be so small that it can remain in prolonged session and give to the various subjects under consideration that deliberate 
attention which has not been possible under the existing scheme of organization during the last forty years. It recognizes the paramount importance of the scientific feature of our work by relieving the general meetings and the sections alike of the troublesome details that now consume the limited and valuable time of the sessions. It remedies the glaring and serious defects in the present constitution. It prepares the Association, by perfecting the organization, to meet important and pressing questions. These considerations, together with the fact that the existing constitutional provision, relative to delay of action on pending amendments, has been met by the appointment, a year ago, of a committee for the avowed and published purpose of reorganization, and by the action of the committee in laying the results of its work before every member of the Association-I say these considerations and these facts prompt me to advise the adoption of the proposed Constitution and By-Laws in their entirety at the present annual session of the Association.

The Committee on Reorganization, under the restrictions of the resolution creating it, has, very properly, left undisturbed the existing rules of conduct. These, if construed to have a fundamental importance, and if vigorously enforced as they now stand, would disintegrate the Association in a single day. This reason, and others already given, confirm me in the conviction that such rules should be either amended or abrogated, or, if reaffirmed, it should be by general resolution endorsing their underlying principles, but disclaiming the present applicability of their details. There are, however, various views entertained upon this subject, and that the matter may be approached in a spirit of tolerance, that it may be discussed coolly and impartially, that a consensus may be reached, and that harmony may be attained, I recommend that the general questions of the revision of the rules of conduct be referred to a special committee on ethics, consisting of three members, with instructions to report to the legislative body at the next annual session of the Association.

THE NEW SCHOOL OF MEDICINE.

The changes which I have advocated are essential for the attainment of the purposes of the Association and for the fulfillment of the high destiny of our national profession. They are demanded by the changes that have taken place during the last fifty years. The legislative functions have passed from voluntary organizations to the Congress and the Legislatures where they belong; but it still devolves upon the profession in the organized capacity to stimulate, to restrain, or otherwise to control the law-making power. The responsibility of the profession is increased, rather than diminished. Science has come to have a clearer meaning. He who now proclaims a dogma cries alone in the night, while the world sleeps. They who demand a creed may read its varying terms only in the progressive revelation of natural laws. Practice has changed. The depletions, the gross medications, the absurd attenuations, the ridiculous anti-mineralism have given away to a refined pharmacy and to a more rational therapy. Sacrificial surgery has yielded to the spirit of conservatism. Prevention is given precedence over cure. Education implies research and discovery, and all may delve. I proclaim, events proclaim, the existence of a new school of medicine. It is as distinct from the schools of fifty years ago as is the Christian dispensation from its pagan antecedents. It is the product of convergent influences, of diverse antecedent origin. It acknowledges no distinctive title, it heralds no shibboleth. It is a school of human tolerance, of personal independence, of scientific honesty. It is 
the slave of neither prejudice nor preconception and abandons the accepted truth of yesterday if only it be the demonstrated error of to-day. It places no premium upon personal prerogative, and extends no recognition to individual authority. It makes no proclamation of completeness, no pretension to sufficiency. It recognizes that truth is undergoing progressive revelation, not ending to-day, but continuing through the ages. It yields its plaudits to achievement, and recognizes that he is the greatest among men who reveals the most of truth unto men. It greets as a friend him who thinks, though he think error, for, thinking, he may think truth and thereby add to the common fund. It heeds all things, examines all things, judges all things.

To you, the exponents of this new school, of this new generation, of this new century; to you, representatives of the Democracy of Science; to you, citizens of the Republic of Letters, I extend greetings; and here, in our parliament assembled, here, where our will is supreme, I this day invoke upon our deliberations the spirit of liberty, the spirit of courage, the spirit of progress, the spirit of truth.

Charles A. L. Reed.

\section{VARIATTONS IN THE APICAL PLATES OF ARBACIA PUNCTULATA FROM WOOD'S HOLL, MASS.}

THE object of this note is to call the atteution of naturalists to three points of variation in the apical system of the common eastern sea-urchin, Arbacia punctulata. The variations may be already known, but I had not noticed them till a year ago, and have never seen any mention of them in print. The observations are based on the study of sixty-three dry specimens sent me for class use from Wood's Holl, Massachusetts, by Mr. F. W. Walmsley. The different plates can be seen very readily if, after removing the spines, the surface be washed and gently brushed with a weak solution of caustic potash and then dried. Great care is necessary in handling the anal plates or they will fall out. The drawings were all made under a camera lucida, magnified four diameters and then reduced one-third. The views are all placed in a similar position, $i$. e., the anterior radius (as defined by Lang's 'TextBook of Comparative Anatomy') is with the madreporic plate in the right anterior interradius. The views are arranged so that all those having four anal plates are in the center and those with three or five are below or above. This figure is a view of the

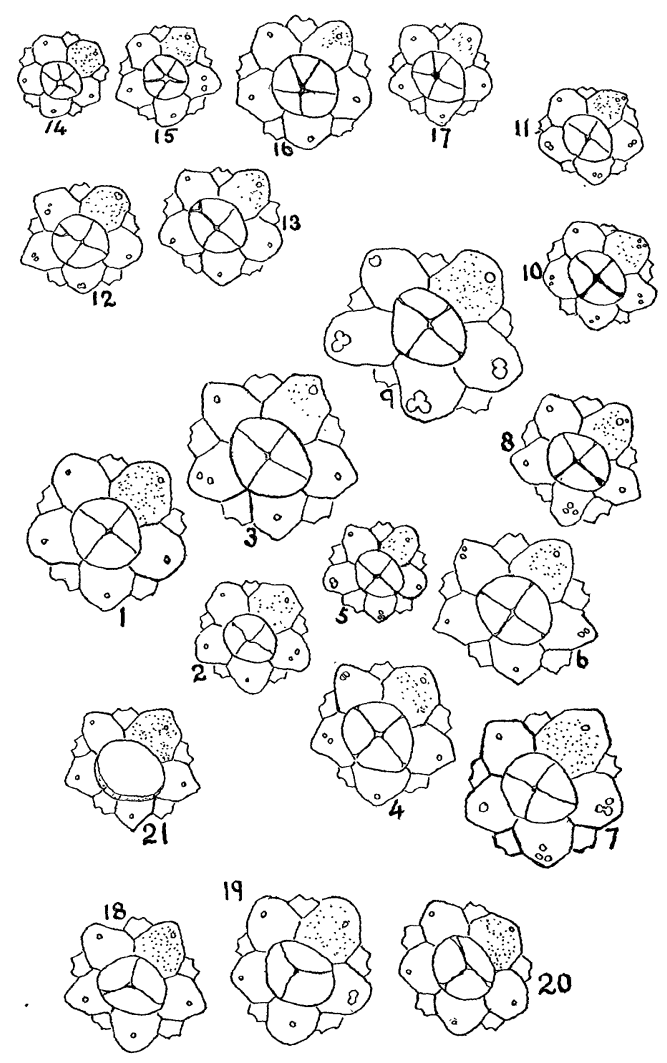

arrangement of apical plates most frequently found, the 'mode,' as it is called by recent writers on variation. It was selected to represent forty-five cases with 